Jurnal Ilmiah Ibnu Sina, 6(2), Oktober 2021, 176-185

p-ISSN: 2502-647X; e-ISSN: 2503-1902

\title{
SKRINING SENYAWA INHIBITOR H2 DARI KAYU MANIS (Cinnamomum verum J.Presl)
}

\author{
Samsul Hadi ${ }^{1 *}$, Diah Aulia Rosanti ${ }^{1}$, Desiya Ramayanti Azhara ${ }^{1}$, \\ Kunti Nastiti ${ }^{2}$ \\ ${ }^{1}$ Prodi Farmasi, Universitas Lambung Mangkurat \\ ${ }^{2}$ Prodi Farmasi, Universitas Sarimulia \\ *Email: samsul.hadi@ulm.ac.id
}

Artikel diterima: 06 Maret 2021; Disetujui: 01 Oktober 2021

DOI: https://doi.org/10.36387/jiis.v6i2.663

\begin{abstract}
ABSTRAK
Gangguan saluran pencernaan khususnya gangguan lambung sering dialami masyarakat. Salah obat untuk mengatasi gangguan ini mempunyai mekanisme menghambat reseptor $\mathrm{H} 2$. Penelitian ini dilakukan untuk mencari senyawa dari C.verum yang mempunyai kestabilan berikatan dengan reseptor $\mathrm{H} 2$. Metode yang digunakan adalah pemodelan protein dengan swiss-model, docking dengan PLANTS (CHEMPLP) dan prediksi aktivitas. Hasil uji yang diperoleh pada skor docking adalah $\alpha$-amorphene (-65,79), $\alpha$-bergamotene $(-65,48), \alpha$-copaene (66,62), $\alpha$-cubebene $(-66,46)$, Cadinene (-64,79), Camphor (-52,15), Caryophyllene $(-62,61)$, Cinnamaldehyde (-68,17), Epicatechin (-80,43), Ergosterol (-85,24), Eugenol (-67,35), Hydrocinnamaldehyde (-65,53), Kuersetin (-74,38), Protocatechuic acid (-71,49), Stigmasterol (-88,88), 4-[2,3-dihydro-3(hydroxymethyl)-5-(3-hydroxypropyl)-7-(methoxy)benzofuranyl]-2-methoxyphenyl $(-85,29)$. Dikombinasikan dengan probability activity senyawa yang berpotensi untuk dikembangkan lebih lanjut adalah Epicatechin dan urolignoside.
\end{abstract}

Kata kunci: Reseptor H2, C.verum, Skor Docking

\begin{abstract}
Digestive tract disorders, especially gastric disorders, are often experienced by people. One drug to treat this disorder has a mechanism of blocking the $\mathrm{H} 2$ receptor. This research was conducted to find compounds from C.verum which have the stability of bind to $\mathrm{H} 2$ receptors. The method used is protein modeling with swiss-model, docking with PLANTS (CHEMPLP) and activity prediction. The test results obtained that the docking score was $\alpha$-amorphene $(-65,79), \alpha$-bergamotene $(-65,48), \alpha$-copaene $(-66,62), \alpha$-cubebene $(-66,46)$, Cadinene $(-64,79)$, Camphor (-52.15), Caryophyllene (-62.61), Cinnamaldehyde (-68.17), Epicatechin (-80.43), Ergosterol (-85.24), Eugenol (-67.35), Hydrocinnamaldehyde (-65,53), Quercetin (-74,38), Protocatechuic acid (-71,49), Stigmasterol (-88,88), 4- (2,3-dihydro-3(hydroxymethyl) - 5- (3-hydroxypropyl) -7- (methoxy) benzofuranyl] -2methoxyphenyl $(-85,29)$. Combined with the probability activity of compounds that have the potential to be further developed are Epicatechin and urolignoside.
\end{abstract}


Jurnal Ilmiah Ibnu Sina, 6(2), Oktober 2021, 176-185

p-ISSN: 2502-647X; e-ISSN: 2503-1902

Keywords: H2 receptor, C.verum, docking score

\section{PENDAHULUAN}

Gangguan kesehatan yang sering dialami oleh masyarakat salah satunya adalah gangguan saluran pencernaan khususnya gangguan lambung. Naiknya asam lambung melewati batas normal merupakan faktor penyebab gastritis yang berhubungan dengan reseptor $\mathrm{H} 2$. Oleh karena itu, diperlukan senyawa yang mampu menghambat sekresi asam lambung. Senyawa yang mampu menghambat produksi asam lambung merupakan senyawa antagonis yang berikatan dengan reseptor H2 (Schubert \& Peura, 2008). Prinsip penelitian ini adalah mencari stabilitas pengikatan senyawa terhadap reseptor $\mathrm{H} 2$. Sehingga berpotensi menurunkan cAMP dalam sirkulasi darah dan mengurangi produksi asam lambung (Azis, 2002).

Obat yang lazim diresepkan oleh dokter yang memiliki aktivitas menurunkan produksi asam lambung adalah menghambat pengikatan histamin (reseptor H2) contohnya ranitidin (Azis, 2002). Mekanisme ranitidin yang sudah diketahui, memungkinkan skrining senyawa secara komputasi untuk menguatkan penggunaan herbal dalam masyarakat. Salah satu tanaman yang digunakan dalam membantu mengatasi gangguan lambung adalah kayu manis (C. verum).

Kandungan kimia $C$. verum sudah banyak ditemukan diantaranya $\alpha$-amorphene, $\alpha$-bergamotene, $\alpha$ copaene, $\alpha$-cubebene, cadinene, camphor, caryophyllene, cinamadehyde, ergosterol, eugenol, hydrocinnamaldehyde, stigmasterol (Rao \& Gan, 2014), kuersetin, epicatechin, protocatechuic acid, urolignoside (Jayaprakasha et al., 2006). Selain digunakan oleh masyarakat dalam mengatasi ganguan lambung, C. verum juga memiliki manfaat mencegah terjadinya kanker kolon (Wondrak et al., 2010), C. verum memiliki kemampuan antioksidan (Hossein et al., 2013), meningkatkan sirkulasi darah (Minich \& Msom, 2008), antimikroba (Chang et al., 2001) anti fungal (Wang et al., 2005), anti inflamasi (Chao et al., 2005), dan anthelmintes (Park et al., 2005). 
Jurnal Ilmiah Ibnu Sina, 6(2), Oktober 2021, 176-185

p-ISSN: 2502-647X; e-ISSN: 2503-1902

\section{METODE PENELITIAN}

\section{Alat dan Bahan}

Laptop yang dipakai dengan spesifikasi prosesor Intel® Quad core Processor N3700, RAM 2GB, Windows 10 64-bit. Perangkat lunak yang digunakan adalah PLANTS (CHEMPLP) (Korb et al., 2009). Marvin Beans Suite.

\section{Subjek Penelitian}

Protein target yang digunakan pada penelitian ini adalah pemodelan protein menggunakan swiss-model dari UniProtKBAC: P25021 dengan template 2ycw.2.A ( $\beta$-adrenergic receptor). Pada struktur kristal tidak ditemukan ligan yang berikatan dengan protein ini sehingga diperlukan docking ranitidine terhadap protein dengan bantuan patchdock (Schneidman-Duhovny et al., 2005; Duhovny et al., 2002).

\section{Prosedur Penelitian}

Ligan disiapkan dengan menggunakan Marvin Beans Suite sehingga diperoleh struktur yang siap dijalankan di PLANTS, sedangkan protein yang diperoleh dari database dipreparasi di YASARA.

\section{Validasi Metode Docking}

Validasi docking ligand dipersiapkan untuk mencari konformasi ligan yang stabil terhadap reseptor dengan melihat koordinat center dan radius. Dalam penelitian ini melihat RMSD (root mean square deviation) untuk melihat kesejajaran konformasi, dan dapat diterima dengan nilai dibawah $2^{0} \mathrm{~A}$ dengan redocking,

\section{Prediksi antiulcerative}

Prediksi antiulcerative menggunakan web server dengan target minimal nilai pa $>0,3$ (Marwaha et al., 2007).

\section{Analisis data}

Analisis data dilakukan dengan melihat skor docking dan interaksi dengan residu. Semakin minus nilai skor docking, maka akan semakin stabil interaksi (Saputri et al., 2016).

\section{HASIL DAN PEMBAHASAN}

Skrining stabilitas ikatan $C$. verum dimulai dengan persiapan protein HRH2 dengan kode 25021 dan pemodelan dilakukan dengan swiss-model dengan template 2ycw.2.A karena memiliki tingkat kemiripan tertinggi dengan protein 
Jurnal Ilmiah Ibnu Sina, 6(2), Oktober 2021, 176-185

p-ISSN: 2502-647X; e-ISSN: 2503-1902

ID: 25021 yaitu nilai identitasnya 36,95 dan GMQE 0,61 dengan global quality estimate adalah Qmean :-4,26; $\mathrm{C} \beta:-2,99$; All atom :0,21; solvation $: 1,30 ;$ torsion: $-4,43$. Setelah mendapatkan model tiga (3) dimensi protein, tahap selanjutnya adalah docking dengan ranitidin di patchdock.

Hasil docking dari patchdock kemudian digunakan sebagai model docking dengan PLANTS dengan mendapatkan center dari ligan yaitu $\mathrm{x}: 16,133, \mathrm{y}:-7,72872, \mathrm{z}: 32,484$ dengan radius 14,4437 . Sehubugan dengan pelepasan ligan dari kompleks protein-ranitidin dari hasil patchdock.

Ligan ini sudah berisi koordinat untuk docking $C$. verum. Tahap selanjutnya adalah validasi docking, yang perlu diperhatikan dari proses validasi ini adalah pelepasan ligan dari kompleks ligan-protein. Ligan ini tidak dapat didocking secara langsung dengan metode PLANTS, karena adanya peringatan inconsisten molecular structure maka struktur ligan diperbaiki di Marvin-Beans. Docking menggunakan PLANTS dijalankan dengan 100 konformer untuk mencari konformasi yang nilai
RMSD nya di bawah $2^{0} \mathrm{~A}$ terhadap kompleks ligan-protein. Dari proses validasi ini diperoleh nilai RMSD $1,1269^{\circ} \mathrm{A}$ (dapat dilihat pada Gambar 2), sehingga metode docking ini dapat dipergunakan lebih lanjut.

Validasi docking (kuning ligand patchdock, merah redocking PLANTS). Nilai skor docking dari ranitidin adalah $-88,82$ dengan binding site residu asam amino: PHE56, SER59, CYS102, TRP247, ILE106, LEU60, ASN284, SER105, ASN280, PHE243, TRP247, ASP64, dilihat dari interaksi dengan residu, ranitidin memiliki berbagai macam interaksi yaitu ikatan hidrogen, interkasi hidrofob, unfavorable bump, pi-lone pairl pi-sulfur dan elektrostatik. Berdasarkan center tempat pengikatan dan radius dari referensi ranitidin maka docking senyawa yang terkandung dapat dimulai dari $\alpha$-amorphene senyawa ini memiliki skor docking 65,79 dengan kesamaan ikatan dengan ranitidin sebesar 50\% yaitu asam amino LEU60, ILE106, PHE243, TRP247, ASN280, CYS102. $\alpha$ bergamotene memiliki skor docking 65,48 jika dikomparatif kan 
Jurnal Ilmiah Ibnu Sina, 6(2), Oktober 2021, 176-185

p-ISSN: 2502-647X; e-ISSN: 2503-1902

pengikatan dengan ranitidin sebesar $33 \%$, dengan residu asam amino yang sama yaitu LEU60, PHE243, TRP247, ASN280. $\quad \alpha$-copaene memiliki skor docking 66,62 dengan kesamaan residu asam amino sebesar $50 \%$ dan residu yang sama yaitu CYS102, ILE106, LEU60, PHE243, TRP247, dan ASP64. $\alpha$-cubebene memiliki skor docking 66,46 dengan kesamaan residu asam amino sebesar $50 \%$ dan residunya yaitu CYS102, LEU60, ILE106, PHE243, TRP247, dan ASP64. Cadinene memilliki skor docking 64,79 dengan persamaan residu asam amino sebesar 58\% dengan residu asam amino yaitu ILE106, PHE243, TRP247, ASP64, SER105, dan LEU60. Camphor memiliki skor docking 52,15 dengan persamaan residu asam amino sebesar $50 \%$ dan residu asam aminonya adalah ASN280, LEU60, ILE106, PHE243, TRP 247, dan SER105.

Caryophyllene memiliki skor docking 62,61 dengan kesamaan asam amino sebesar 50\% dan residu asam amino yaitu: LEU60, PHE243, TRP247, ILE106, SER105, ASN 280. Cinnamaldehyde memiliki skor docking 68,17 dengan persamaan residu asam amino yaitu $0,33 \%$ dan residunya adalah ASP64, SER105, PHE243, dan LEU60. Epicatechin memiliki skor docking 80,43 dengan persamaan sebesar $75 \%$ dengan residu asam aminonya adalah ASN280, LEU60, CYS102, TRP247, ASP64, ASN284, SER105, PHE243, dan ILE106. Ergosterol memiliki skor doking 85,24 dengan persamaan sebesar $50 \%$ dan residu asam amino adalah LEU60, ILE106, PHE243, TRP247, ASN280, dan SER105. Eugenol memiliki skor docking sebesar 67,35 dengan persamaan sebesar 66,66\% dan residu asam aminonya adalah ASN280, ASP64, CYS102, LEU60, PHE243, TRP247, LEU60, dan SER105. Hydrocinnamaldehyde memiliki skor docking 65,53 persamaan asam amino sebesar $25 \%$ asam amino yang sama yaitu IL106, LEU60, LEU109, dan SER105. Kuersetin memiliki skor docking sebesar 74,38 dengan persamaan sebesar $41 \%$ dan residu asam amino adalah ILE106, CYS102, LEU60, SER105, TRP247 dan PHE243. 
Jurnal Ilmiah Ibnu Sina, 6(2), Oktober 2021, 176-185

p-ISSN: 2502-647X; e-ISSN: 2503-1902

Tabel 1. Skor Docking dan Interaksi dengan Residu Asam Amino

\begin{tabular}{|c|c|c|c|c|}
\hline Nama Senyawa & $\begin{array}{c}\text { Scor } \\
\text { Docking }\end{array}$ & Hidrogen & Hidrofob & $\begin{array}{l}\text { Unfavorable bump/pi } \\
\text {-lone pair/ pi-sulfur/ }\end{array}$ \\
\hline$\alpha$-amorphene & $-65,79$ & & $\begin{array}{l}\text { LUE60, ILE106, } \\
\text { LEU109, LEU 67, } \\
\text { PHE 243, TRP247 }\end{array}$ & $\begin{array}{l}\text { ASN280, SER105, } \\
\text { CYS } 102\end{array}$ \\
\hline$\alpha$-bergamotene & $-65,48$ & & $\begin{array}{l}\text { LEU109, LEU60, } \\
\text { PHE243, TRP247 }\end{array}$ & $\begin{array}{l}\text { ASN280, THR63, } \\
\text { SER60 }\end{array}$ \\
\hline$\alpha$-copaene & $-66,62$ & & $\begin{array}{l}\text { CYS102, LEU109, } \\
\text { ILE106, LEU109, } \\
\text { LEU60, PHE243, } \\
\text { TRP247 }\end{array}$ & LEU101, ASP64 \\
\hline$\alpha$-cubebene & $-66,46$ & & $\begin{array}{l}\text { CYS102, LEU109, } \\
\text { LEU60, ILE106, } \\
\text { LEU109, PHE243, } \\
\text { TRP247, }\end{array}$ & ASP64, SER105 \\
\hline Cadinene & $-64,79$ & & $\begin{array}{l}\text { ILE106, PHE243, } \\
\text { TRP247 }\end{array}$ & $\begin{array}{l}\text { PHE243, ASN289, } \\
\text { ASP64, SER105, } \\
\text { LEU60 }\end{array}$ \\
\hline Camphor & $-52,15$ & ASN28 & $\begin{array}{l}\text { LEU60, ILE106, } \\
\text { LEU109, PHE243, } \\
\text { TRP247 }\end{array}$ & SER 105 \\
\hline Caryophyllene & $-62,61$ & & $\begin{array}{l}\text { LEU109, LEU67, } \\
\text { LEU60, PHE243, } \\
\text { TRP247 }\end{array}$ & $\begin{array}{l}\text { ILE106, SER105, } \\
\text { ASN280 }\end{array}$ \\
\hline Cinnamaldehyde & $-68,17$ & ASP64, SER105 & ILE106 & $\begin{array}{l}\text { LEU67, PHE243, } \\
\text { LEU109, LEU60 }\end{array}$ \\
\hline Epicatechin & $-80,43$ & $\begin{array}{l}\text { ASN280, LEU60, } \\
\text { CYS102 }\end{array}$ & \multicolumn{2}{|c|}{$\begin{array}{l}\text { TRP247, ASP64, ASN284, SER105, PHE243, } \\
\text { ILE106 }\end{array}$} \\
\hline Ergosterol & $-85,24$ & GLY277 & $\begin{array}{l}\text { LEU109, CYS246, } \\
\text { LEU67, LEU60, } \\
\text { ILE106, PHE243, } \\
\text { TRP247 }\end{array}$ & $\begin{array}{l}\text { ASN280, ASN108, } \\
\text { SER105, SER59 }\end{array}$ \\
\hline Eugenol & $-67,35$ & ASN280, ASP64, & $\begin{array}{l}\text { CYS102, LEU60, } \\
\text { PHE243, TRP247, } \\
\text { LEU60 }\end{array}$ & SER 105 \\
\hline $\begin{array}{l}\text { Hydrocinnamal } \\
\text { dehyde }\end{array}$ & $-65,53$ & & ILE106, LEU60 & $\begin{array}{l}\text { LEU67, LEU109, } \\
\text { SER105 }\end{array}$ \\
\hline Kuersetin & $-74,38$ & $\begin{array}{l}\text { LEU109, } \\
\text { GLY277, ALA61, } \\
\text { ILE106 }\end{array}$ & LEU109, CYS102 & $\begin{array}{l}\text { LEU60, SER105, } \\
\text { TRP247, PHE } 243\end{array}$ \\
\hline $\begin{array}{l}\text { Protocatechuic } \\
\text { acid }\end{array}$ & $-71,49$ & $\begin{array}{l}\text { TRP247, } \\
\text { CYS102, ASP64 }\end{array}$ & LEU109 & $\begin{array}{l}\text { ILE106, LEU60, } \\
\text { PHE243, ASN280, } \\
\text { SER105 }\end{array}$ \\
\hline Stigmasterol & $-88,88$ & TYR278 & $\begin{array}{l}\text { ILE106, LEU109, } \\
\text { LEU67, LEU109, } \\
\text { LEU60, PHE243, } \\
\text { TRP247 }\end{array}$ & $\begin{array}{l}\text { ASN280, SER281, } \\
\text { ALA282, ASP64, } \\
\text { SER105, ASN108, } \\
\text { LEU107 }\end{array}$ \\
\hline Urolignoside & $-85,29$ & $\begin{array}{l}\text { ASN280, } \\
\text { CYS102, } \\
\text { SER105, GLY277 }\end{array}$ & $\begin{array}{l}\text { LEU60, LEU67, } \\
\text { TRP247, TYR278, } \\
\text { LEU109 }\end{array}$ & $\begin{array}{l}\text { LEU109, ASN108, } \\
\text { THR63, ILE106, } \\
\text { PHE243 }\end{array}$ \\
\hline Ranitidin & $-88,82$ & $\begin{array}{l}\text { PHE56, SER59, } \\
\text { CYS102, }\end{array}$ & TRP247, ILE106 & $\begin{array}{l}\text { LEU60, ASN284, } \\
\text { SER105, ASN280, } \\
\text { PHE243, TRP247, } \\
\text { ASP64 }\end{array}$ \\
\hline
\end{tabular}


Jurnal Ilmiah Ibnu Sina, 6(2), Oktober 2021, 176-185

p-ISSN: 2502-647X; e-ISSN: 2503-1902

Protocatechuic acid memiliki skor docking sebesar 71,49 dengan persamaan asam amino sebesar $66 \%$ dan residu asam amino yaitu TRP247, CYS102, ASP64, ILE106, LEU60, PHE243, ASN280, dan SER105. Stigmasterol memliki skor docking 88,88 dengan persamaan asam amino sebesar $58 \%$ dan residu asam amino adalah ILE106, LEU60, PHE243, TRP247, ASN 280, ASP64, dan SER105. Urolignoside memiliki skor docking 85,29 dengan persamaan asam amino sebesar $58 \%$ dan residu asam amino yaitu ASN280, CYS102, SER105, LEU60, TRP247, ILE106, dan PHE243.

Skor docking antara senyawa ergosterol, stimasterol dan urolignoside memiliki skor docking yang besar, tetapi memiliki kemiripan residu asam amino dibawah $75 \%$. Hal ini karena ketiga senyawa tersebut memiliki struktur yang bulky sehingga mampu menduduki residu asam amino dalam jumlah besar, untuk ergosterol mampu menduduki 12 asam amino, stigmasterol mampu menduduki residu asam amino sebesar 15, dan urolignoside mempu menduduki asam amino sebesar 13 .

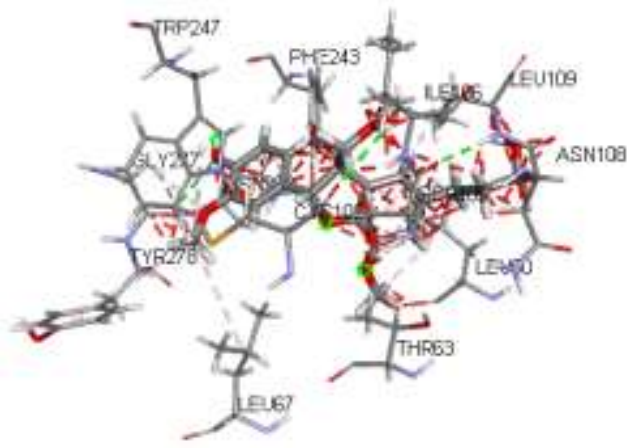

Gambar 1. Interaksi Urolignoside dengan Residu Asam Amino

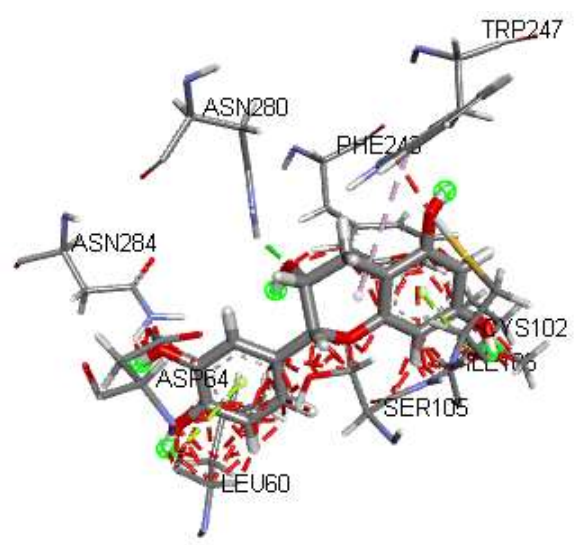

Gambar 2. Interaksi Epicatechin dengan Residu Asam Amino

Ligan Epicatechin memiliki skor docking $90 \%$ dibandingkan dengan skor docking ranitidin, hal ini dikarenakan berat molekulnya relatif kecil yaitu 290,27 g/mol, sehingga ketika melawati membran sel target relatif mudah. Tahap selanjutnya adalah memperdiksi aktivitas mengenai antiulcerative, target dari kandungan kimia memiliki nilai probability diatas 0,3 . 
Tabel 2. Prediksi Aktivitas

\begin{tabular}{|c|c|c|}
\hline Nama Senyawa & $\mathbf{P a}$ & $\mathbf{P i}$ \\
\hline$\alpha$-amorphene & 0,376 & 0,055 \\
\hline$\alpha$-bergamotene & 0,446 & 0,033 \\
\hline$\alpha$-copaene & - & - \\
\hline$\alpha$-cubebene & - & - \\
\hline Cadinene & 0,262 & 0,133 \\
\hline Camphor & - & - \\
\hline Caryophyllene & 0,535 & 0,018 \\
\hline Cinnamaldehyde & 0,272 & 0,124 \\
\hline Epicatechin & 0,429 & 0,036 \\
\hline Ergosterol & - & - \\
\hline Eugenol & 0,516 & 0,020 \\
\hline Hydrocinnamaldehyde & - & - \\
\hline Kuersetin & 0,321 & 0,083 \\
\hline Protocatechuic acid & 0,389 & 0,049 \\
\hline Stigmasterol & - & - \\
\hline $\begin{array}{l}\text { 4-[2,3-dihydro-3- } \\
\text { (hydroxymethyl)-5-(3- } \\
\text { hydroxypropyl)-7- } \\
\text { (methoxy)benzofuranyl]- } \\
\text { 2-methoxyphenyl }\end{array}$ & 0,621 & 0,09 \\
\hline Ranitidin & 0,987 & 0,001 \\
\hline
\end{tabular}

C. verum yang berpotensi sebagai antiulcerative diatas 0,3 adalah $\alpha$ - amorphene, $\alpha$ bergamotene, Caryophyllene, Epicatechin, Eugenol, Kuersetin, Protocatechuic acid, 4-[2,3-dihydro3-(hydroxymethyl)-5-(3hydroxypropyl)-7 (methoxy) benzo furanyl]-2-methoxyphenyl. Dengan menggabungkan tabel 1 dan tabel 2 maka senyawa yang berpotensi dikembangkan untuk penelitian di laboratorium adalah Epicatechin dan 4-[2,3-dihydro-3-(hydroxylmethyl)-5- (3-hydroxypropyl)-7 (methoxy) benzo furanyl]-2-methoxyphenyl kerena memiliki skor docking diatas $90 \%$ jika dibandingkan dengan ranitidin dan nilai probability activity diatas 3 .

\section{KESIMPULAN}

Berdasarkan hasil skrining komputasi terhadap antagonis $\mathrm{H} 2$ diperoleh dua senyawa yang memiliki skor docking yang tinggi dan probability activity yang besar yaitu Epicatechin dan urolignoside.

\section{UCAPAN TERIMA KASIH}

Kami mengucapkan terimakasih kepada Universitas Lambung Mangkurat, yang telah memberi kesempatan untuk melakukan penelitian ini.

\section{DAFTAR PUSTAKA}

Azis, N. (2002). Peran Antagonis Reseptor H-2 Dalam Pengobatan Ulkus Peptikum. Sari Pediatri, 3, 222-226.

Chang, S.-T., Chen, P.-F., \& Chang, S.-C. (2001). Antibacterial activity of leaf essential oils and their constituents from Cinnamomum osmophloeum. Journal of Ethnopharmacology, 77(1), 123-127. 
Jurnal Ilmiah Ibnu Sina, 6(2), Oktober 2021, 176-185

p-ISSN: 2502-647X; e-ISSN: 2503-1902

Chao, L. K., Hua, K.-F., Hsu, H.-Y., Cheng, S.-S., Liu, J.-Y., \& Chang, S.-T. (2005). Study on the Antiinflammatory Activity of Essential Oil From Leaves of Cinnamomum osmophloeum. Journal of Agricultural and Food Chemistry, 53(18), 72747278.

https://doi.org/10.1021/jf05115 $1 \mathrm{u}$

Duhovny, D., Nussinov, R., \& Wolfson, H. J. (2002). Efficient Unbound Docking of Rigid Molecules. Lecture Notes in Computer Science (Including Subseries Lecture Notes in Artificial Intelligence and Lecture Notes in Bioinformatics), 2452, 185200.

https://doi.org/10.1007/3540-45784-4_14

Hossein, N., Zahra, Z., Abolfazl, M., Mahdi, S., \& Ali, K. (2013). Effect of Cinnamon zeylanicum Essence and Distillate on the Clotting Time. Journal of Medicinal Plants Research, 7(19), 1339-1343. https://doi.org/10.5897/JMPR1 2.1198

Jayaprakasha, G. K., OhnishiKameyama, M., Ono, H., Yoshida, M., \& Rao, L. J. (2006). Phenolic Constituents in the Fruits of Cinnamomum zeylanicum and Their Antioxidant Activity. Journal of Agricultural and Food Chemistry, 54(5), 1672-1679. https://doi.org/10.1021/jf05273 6r

Korb, O., Stützle, T., \& Exner, T. E.
(2009). Empirical Scoring Functions for Advanced Protein-Ligand Docking with PLANTS. Journal of Chemical Information and Modeling, 49(1), 84-96. https://doi.org/10.1021/ci80029 $8 \mathrm{z}$

Marwaha, A., Goel, R. K., \& Mahajan, M. P. (2007). PASSpredicted Design, Synthesis and Biological Evaluation of Cyclic Nitrones as Nootropics. Bioorganic \& Medicinal Chemistry Letters, 17(18), 5251-5255.

https://doi.org/https://doi.org/1 0.1016/j.bmcl.2007.06.071

Minich, S., \& Msom, L. (2008). Chinese Herbal Medicine in Women's Health. Women's Health.

Park, I.-K., Park, J.-Y., Kim, K.-H., Choi, K.-S., Choi, I.-H., Kim, C.-S., \& Shin, S.-C. (2005). Nematicidal Activity of Plant Essential Oils and Components from Garlic (Allium sativum) and Cinnamon (Cinnamomum verum) oils against the pine wood nematode (Bursaphelenchus xylophilus). Nematology, 7(5), 767-774.

Rao, P. V., \& Gan, S. H. (2014). Cinnamon: a multifaceted medicinal plant. EvidenceBased Complementary and Alternative Medicine: ECAM, 2014, 642942. https://doi.org/10.1155/2014/6 42942

Saputri, K. E., Fakhmi, N., Kusumaningtyas, E., Priyatama, D., \& Santoso, B. 
Jurnal Ilmiah Ibnu Sina, 6(2), Oktober 2021, 176-185

p-ISSN: 2502-647X; e-ISSN: 2503-1902

(2016). Docking Molekular Potensi Anti Diabetes Melitus Tipe 2 Turunan Zerumbon Sebagai Inhibitor Aldosa Reduktase dengan AutodockVina. Chimica et Natura Acta, 4(1), 16. https://doi.org/10.24198/cna.v4 .n1.10443

Schneidman-Duhovny, D., Inbar, Y., Nussinov, R., \& Wolfson, H. J. (2005). PatchDock and SymmDock: Servers for Rigid and Symmetric Docking. Nucleic Acids Research, 33(Web Server issue), W363-7. https://doi.org/10.1093/nar/gki 481

Schubert, M. L., \& Peura, D. A. (2008). Control of Gastric Acid Secretion in Health and Disease. Gastroenterology, 134(7), 1842-1860. https://doi.org/https://doi.org/1 0.1053/j.gastro.2008.05.021
Wang, S.-Y., Chen, P.-F., \& Chang, S.-T. (2005). Antifungal Activities of Essential Oils and Their Constituents from Indigenous Cinnamon (Cinnamomum osmophloeum) Leaves Against Wood Decay Fungi. Bioresource Technology, 96(7), 813-818.

Wondrak, G. T., Villeneuve, N. F., Lamore, S. D., Bause, A. S., Jiang, T., \& Zhang, D. D. (2010). The Cinnamon-derived Dietary Factor Cinnamic Aldehyde Activates the Nrf2dependent Antioxidant Response in Human Epithelial Colon Cells. Molecules (Basel, Switzerland), 15(5), 33383355.

https://doi.org/10.3390/molecul es 15053338 